\title{
Generasi Berencana Peduli Organ Reproduksi Perempuan (GenRe POP) Dalam Meningkatkan Personal Menstrual Hygiene Pada Remaja
}

\author{
${ }^{1}$ Veronica Yeni Rahmawati, ${ }^{2}$ Jehan Puspasari, ${ }^{3}$ Ernawati, ${ }^{4}$ Casman, \\ ${ }^{5}$ Mellyani Eka Sari, ${ }^{6}$ Rici Rianjar \\ 1,2,3,4,5,6Program Studi Diploma Tiga Keperawatan, Sekolah Tinggi Ilmu Kesehatan RS Husada Jakarta \\ Korespondensi: vero@stikesrshusada.ac.id
}

\begin{abstract}
Adolescents are at risk of health problems, especially when they face signs of adolescent development during puberty, namely menstruation. Adolescents tend to be less likely to maintain personal hygiene during menstruation (personal menstrual hygiene). Improper behavior in personal menstrual hygiene in adolescents can cause reproductive tract infections and other health problems. The purpose of this activity is to increase the knowledge and insight of adolescents in general to maintain personal hygiene during menstruation. The method of this activity is divided into several steps, starting with the socialization of the activity agenda, providing educational materials to teenagers through Zoom meetings, edutainment of the snake and ladder game on the carpet in the courtyard of the mosque area and finally a discussion (FGD) for mothers of teenagers about personal menstrual hygiene. The result of this activity is an increase in knowledge of personal menstrual hygiene in adolescents before and after attending education. Providing education that is packaged with a snake and ladder game model is proven to be effective in increasing adolescent knowledge about personal menstrual hygiene.

Keywords: personal menstrual hygiene, snake ladder edutainment, community service.
\end{abstract}

\begin{abstract}
Abstrak:Remaja berisiko terhadap permasalahan kesehatan terutama menghadapi tanda-tanda perkembangan remaja di masa pubertas yaitu menstruasi. Remaja cenderung kurang memelihara kebersihan diri pada saat menstruasi (personal menstrual hygiene). Perilaku yang tidak tepat dalam personal menstrual hygiene pada remaja dapat menyebabkan Infeksi Saluran Reproduksi dan masalah kesehatan lainnya. Tujuan dari kegiatan ini yaitu meningkatkan pengetahuan dan wawasan remaja pada umumnya untuk menjaga kebersihan diri saat menstruasi. Metode kegiatan ini terbagi dalam beberapa langkah, diawali sosialisasi agenda kegiatan, memberikan materi edukasi pada remaja melalui Zoom meeting, edutainment permainan ular tangga karpet di halaman area Masjid dan terakhir diskusi (FGD) bagi para ibu dari remaja tentang personal menstrual hygiene. Hasil dari kegiatan ini adalah terlihat peningkatan pengetahuan personal menstrual hygiene pada remaja sebelum dan sesudah mengikuti edukasi. Pemberian edukasi yang dikemas dengan model permainan ular tangga terbukti efektif meningkatkan pengetahuan remaja tentang personal menstrual hyiene.
\end{abstract} Kata kunci: personal menstrual hygiene, edutainment ular tangga karpet, pengabdian kepada masyarakat.

\section{PENDAHULUAN}

Remaja merupakan aset negara yang perlu mendapat perhatian. Remaja adalah penduduk dengan rentang usia 10-24 tahun. Menurut data survei dunia jumlah remaja terhitung cukup besar dari seluruh populasi di dunia. Mayoritas jumlah terbanyak anak dengan rentang usia 10-19 tahun. Di Indonesia, populasi generasi $Z$ mencapai 75,49 juta orang atau $27,94 \%$ dari jumlah penduduk Indonesia ${ }^{1}$.

Remaja putri memiliki curiosity yang tinggi, senang mencoba hal yang baru dan masa pencarian jati diri berhubungan dengan pubertas. Remaja rentan mengalami masalah dalam kesehatannya terutama menghadapi tanda-tanda perkembangan remaja memasuki masa pubertas yaitu mulainya menstruasi.

Anak perempuan yang masih usia sekolah dasar merupakan kelompok rentan terjadinya penyakit infeksi sistem reproduksi karena kurangnya informasi kesehatan, belum matang secara sosial dan status fisik.2 Sebagian besar masyarakat, terutama di negara berkembang, kurang tepat atau kurang memadai dalam memberikan informasi menghadapi proses menstruasi, serta perubahan fisik dan psikologis maupun kebersihan diri pada saat menstruasi mengakibatkan konsekuensi yang buruk seperti perilaku tidak sehat, gambaran diri negatif, rentan terjadinya infeksi saluran reproduksi (ISR), penyakit radang panggul (pelvic inflammatory diseases), infertilitas, kecemasan, harga diri rendah, dan lain-lain ${ }^{3}$.

Berdasarkan data yang dihimpun melalui penelitian yang dilakukan oleh Azzahra \& Adiwiryono 4 . menunjukkan bahwa 76,6\% remaja putri yang bersekolah di SMP PGRI Depok II Tengah Jawa Barat memiliki personal menstrual hygiene kurang baik. Ditambah adanya penelitian oleh Amanda \& Ariyanti ${ }^{5}$. yang menyebutkan bahwa $54,5 \%$ santriwati di pondok pesantren modern Kota Depok memiliki personal menstrual hygiene yang buruk.

This is an open-access article under the CC BY 4.0 International License

(c) Idea PengabdianMasyarakat (2022)

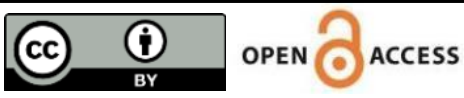


Remaja mempunyai masalah terkait memelihara kebersihan diri pada saat menstruasi (personal menstrual hygiene) akibat kurangnya informasi dan edukasi khususnya personal menstrual hygiene. Hal ini menyebabkan rasa ketidaknyamanan serta tidak percaya diri pada masa menstruasi, apabila hal ini tidak segera ditindaklanjuti maka akan menjadi masalah yang signifikan di antara para remaja.

Pemerintah kota Depok telah melakukan berbagai program maupun kegiatan untuk mencapai salah satu misi yaitu Kota Depok Ramah Anak. Untuk mencapai misi tersebut maka dibutuhkan peran dari berbagai pihak. Hal ini sejalan dengan program dari pemerintah yang meluncurkan program GenRe (Generasi Berencana) dalam upaya pembinaan ketahanan remaja. Pemerintah telah berupaya membuat strategi untuk meningkatkan kesehatan remaja putri salah satunya yaitu kesehatan reproduksi.

Remaja diberikan pembinaan oleh lembaga pemerintah melalui edukasi, konseling dan informasi untuk meningkatkan kesehatan remaja. Tujuan dari pembinaan ini adalah terbentuknya Generasi Berencana (GenRe) yang lebih matang dan siap menghadapi perubahan kehidupannya dengan Berencana (GenRe) yang lebih matang dan siap menghadapi perubahan kehidupannya dengan membiasakan perilaku hidup bersih dan sehat, mencapai tingkat pendidikan setinggi-tingginya, bermanfaat untuk orang lain, menjadi contoh remaja yang baik, serta mengembangkan potensi diri.

Berdasarkan latar belakang tersebut maka dibutuhkan forum diskusi untuk saling membagikan pengalaman bagi remaja dan para ibu dari remaja terkait upaya optimalisasi menjaga kesehatan reproduksi perempuan khususnya personal menstrual hygiene pada remaja. Dengan demikian STIKes RS Husada bermaksud mengadakan kegiatan pengabdian kepada masyarakat di bidang maternitas dengan tema "Generasi Berencana Peduli Organ Reproduksi Perempuan (GenRe POP) dalam meningkatkan Personal Menstrual Hygiene pada Remaja.

\section{METODE}

Kegiatan pengabdian kepada masyarakat ini berlangsung mulai dari 29 Oktober-07 November 2021. Lokasi tempat pengabdian kepada masyarakat ini yaitu di RT.007 RW.10 Kecamatan Sukmajaya Kota Depok Jawa Barat. Berikut ini beberapa tahapan dalam pelaksanaannya seperti dijelaskan di bawah ini:

Tabel 1 : Tahapan pelaksanaan pengabdian kepada masyarakat

\begin{tabular}{lll}
\hline No. & Tanggal & Kegiatan \\
\hline 1. & 29 Oktober 2021 & Perijinan ke pihak warga sasaran \\
\hline 2. & 30 Oktober 2021 & Pendataan remaja warga sasaran \\
\hline 3. & 31 Oktober 2021 & Persiapan media dan sarana \\
\hline 4. & 01 November 2021 & Sosialisasi kegiatan pengabdian \\
\hline 5. & 05 November 2021 & $\begin{array}{l}\text { Kegiatan inti hari pertama yaitu materi edukasi } \\
\text { bagi remaja tentang personal menstrual hygiene } \\
\text { via Zoom meeting }\end{array}$ \\
\hline 6. & 06 November 2021 & $\begin{array}{l}\text { Kegiatan inti hari kedua yaitu Edutainment } \\
\text { permainan ular tangga karpet di halaman area } \\
\text { Masjid }\end{array}$ \\
\hline 7. & 07 November 2021 & $\begin{array}{l}\text { Kegiatan inti hari ketiga yaitu diskusi (FGD) } \\
\text { via Zoom meeting bagi para ibu dari remaja } \\
\text { tentang peran ibu dalam meningkatkan } \\
\text { personal menstrual hygiene remaja dan } \\
\text { evaluasi kegiatan. }\end{array}$ \\
\hline
\end{tabular}

This is an open-access article under the CC BY 4.0 International License

(C) Idea PengabdianMasyarakat (2022)

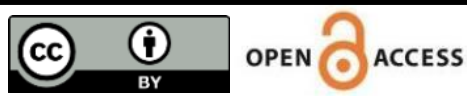


Alat dan media yang dipersiapkan dalam kegiatan ini yaitu laptop, materi edukasi, karpet ular tangga ukuran $4 \times 3 \mathrm{~m}$, buku panduan edutainment permainan ular tangga, dadu bantal ukuran $20 \times 20 \times 20$ $\mathrm{cm}$, flash card dan leaflet. Pengumpulan data dilakukan dengan mengirimkan kuesioner online melalui aplikasi google form sebelum pemberian materi edukasi personal menstrual hygiene sebagai pretest dan sesudah kegiatan edutainment permainan ular tangga karpet sebagai posttest. Instrumen yang digunakan yaitu kuesioner pengetahuan mengenai personal menstrual hygiene yang berisi 20 pertanyaan ${ }^{6}$. Analisis data menggunakan deskriptif analitik dengan memasukkan nilai pre test dan post test untuk menilai keberhasilan program yang dilakukan.

Teknik yang digunakan dalam menetapkan sampel yaitu purposive sampling yang memenuhi kriteria inklusi sebagai berikut yaitu remaja putri dengan rentang usia 10-19 tahun, belum atau sudah menstruasi serta tinggal bersama ibunya. Jumlah sampel dalam kegiatan ini yaitu 16 peserta.

\section{HASIL DAN PEMBAHASAN}

Tahap persiapan

Persiapan dilakukan dengan menyampaikan kepada pengurus RT.07 RW.10 Kecamatan Sukmajaya DepokJawa Barat maksud dan tujuan dari kegiatan pengabdian kepada masyarakat ini, kemudian tim bekerja sama dalam pembuatan media edukasi seperti karpet ular tangga, buku panduan edutainment ular tangga, serta menyiapkan bahan dan alat yang akan digunakan misalnya dadu bantal dan leaflet.

\section{Tahap pelaksanaan}

Kegiatan inti hari pertama yaitu pemberian materi edukasi bagi remaja tentang personal menstrual hygiene via Zoom Meeting . Sebelum memulai kegiatan edukasi, tim mengirimkan kuesioner yang berisi tentang personal menstrual hygiene melalui aplikasi google form kepada para peserta. Kemudian pemberian materi edukasi yang disampaikan oleh Ns. Veronica Yeni Rahmawati, M.Kep.,Sp.Kep.Mat. Kegiatan inti hari kedua yaitu Edutainment permainan ular tangga karpet di area halaman Masjid As-Salam. Kegiatan ini dimulai dengan membacakan aturan permainan, kemudian membagi jumlah peserta untuk bermain secara bergiliran dan menjawab pertanyaan sesuai dengan nomer posisi pemain di dalam ular tangga. Kegiatan inti hari ketiga yaitu diskusi (FGD) via Zoom meeting bagi para ibu dari remaja tentang peran ibu dalam meningkatkan personal menstrual hygiene remaja dan evaluasi kegiatan.

Hasil dari kegiatan ini seperti tabel yang ditunjukkan di bawah ini:

Tabel 1. Hasil Kuesioner Pre test dan Post test Pengetahuan tentang Personal Menstrual Hygiene

\begin{tabular}{|c|c|c|c|c|c|c|c|}
\hline \multirow{4}{*}{$\begin{array}{l}\text { Personal } \\
\text { Menstrual }\end{array}$} & \multicolumn{3}{|c|}{ Pre test } & \multicolumn{4}{|c|}{ Post test } \\
\hline & Pengetahuan Baik & Pen & n Kurang & Pen & uan Baik & & an Kurang \\
\hline & $\mathrm{N} \quad \%$ & $\mathrm{~N}$ & $\%$ & $\mathrm{~N}$ & $\%$ & $\mathrm{~N}$ & $\%$ \\
\hline & 25 & 12 & 75 & 15 & 93,75 & 1 & 6,25 \\
\hline
\end{tabular}

Berdasarkan tabel 1 menunjukkan bahwa remaja yang memiliki pengetahuan baik tentang personal menstrual hygiene diperoleh hasil pre test sebanyak 4 orang $(25 \%)$ sedangkan hasil post test peserta yang memiliki pengetahuan yang baik tentang personal menstrual hygiene diperoleh hasil sebanyak 15 orang $(93,75 \%)$. Dari hasil tersebut menunjukkan terdapat peningkatan pengetahuan peserta setelah dilakukan kegiatan edutainment, sehingga kegiatan GenRe POP (Generasi Berencana Peduli Organ Reproduksi Perempuan) dalam meningkatkan personal menstrual hygiene pada remaja yang dilakukan di RT.007 RW.10 Kec Sukmajaya Depok berhasil dilaksanakan.

This is an open-access article under the CC BY 4.0 International License

(C) Idea PengabdianMasyarakat (2022)

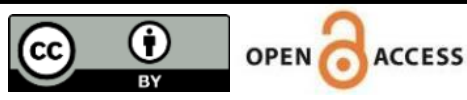



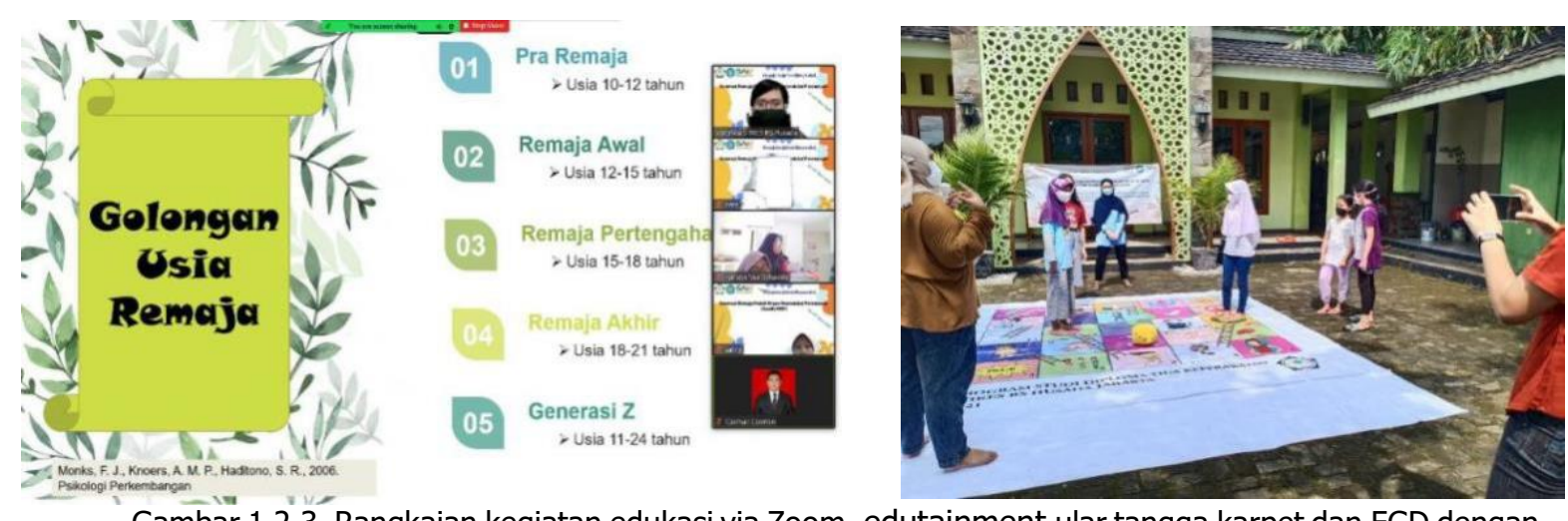

Gambar 1,2,3. Rangkaian kegiatan edukasi via Zoom, edutainment ular tangga karpet dan FGD dengan orang tua dari remaja putri

Kegiatan Generasi Berencana Peduli Organ Reproduksi Perempuan (GenRe POP) dapat menambah pengetahuan remaja tentang pentingnya Personal Menstrual Hygiene. Selain itu ibu dari remaja juga ikut berperan penting sebagai pendidik, pengawas, teman maupun konselor bagi remaja dalam meningkatkan personal menstrual hygiene. Harapan dari kegiatan ini adalah terwujudnya generasi remaja yang peduli terhadap organ reproduksi sejak dini, salah satunya adalah dengan menjaga kesehatan reproduksi pada saat menstruasi dengan personal menstrual hygiene yang baik. Sejalan dengan penelitian Ningsih et $\mathrm{al}^{7}$ menyebutkan pendidikan kesehatan melalui media yang interaktif diyakini dapat diterima oleh remaja putri dalam meningkatkan pengetahuan maupun memahami personal menstrual hygiene. Penelitian Zuhriya et $\mathrm{al}^{8}$, juga mengatakan permainan edutainment ular tangga karpet bagi remaja berpengaruh secara bermakna dalam meningkatkan wawasan dan perilaku remaja putri dalam meningkatkan personal menstrual hygiene.

Edutainment ular tangga karpet merupakan permainan yang sesuai dengan tahapan tumbuh kembang remaja, remaja lebih menyukai permainan yang memiliki unsur edukasi ${ }^{9}$. Isi dalam media ini meliputi cara penggunaan media edutainment ular tangga, pemberian materi yang ada dalam flash card dan pemberian buku pedoman tentang tata cara permainan ular tangga. Materi yang ada dalam permainan ini yaitu mitos dan fakta saat menstruasi, personal menstrual hygiene dan cara menjaga kesehatan reproduksi perempuan. Kegiatan ini dilakukan sebagai bentuk preventif dalam mencegah penyakit akibat hygiene yang buruk. Penerapan personal menstrual hygiene pada remaja dapat meningkatkan kenyamanan dan kepercayaan diri pada remaja putri.

Pengetahuan tentang personal menstrual hygiene harus diberikan dengan tepat dan memadai agar remaja dapat mengetahui dan memahami proses menstruasi yang akan dialami. Strategi yang dilakukan dalam meningkatkan pengetahuan remaja tentang kesehatan dapat diberikan melalui edutainment. Edutainment ular tangga karpet merupakan permainan yang sesuai dengan tahapan tumbuh kembang remaja, remaja lebih menyukai permainan yang memiliki unsur edukasi ${ }^{10}$.

Metode pendidikan kesehatan peer grup, booklet, dan brainstorming merupakan metode yang dapat diterapkan untuk meningkatkan sikap, respon emosional dan keterampilan dalam menerapkan personal menstrual hygiene, namun Kurniawati et al11. lebih merekomendasikan penggunaan metode pendidikan kesehatan sambil bermain yang inovatif dan menarik seperti permainan ular tangga. Permainan ular tangga memungkinkan pemateri lebih mudah dalam menyampaikan materi, antusias remaja putri juga meningkat karena media ini unik dan menarik, serta ada unsur kompetisi yang membuat motivasi remaja meningkat. Kegiatan ini juga melibatkan peran orang tua dalam membina anggota keluarganya yang berusia remaja khususnya remaja putri.

This is an open-access article under the CC BY 4.0 International License

(c) Idea PengabdianMasyarakat (2022)

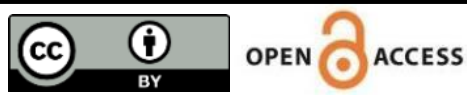




$$
\text { Peran orang tua memiliki pengaruh besar terhadap remaja putri yang }
$$
mengalami menstruasi untuk menanamkan proses reproduksi termasuk cara merawat organ reproduksi. Memberikan pendidikan kesehatan reproduksi kepada remaja putri merupakan cara pandang untuk mencapai reproduksi yang lebih baik, sehingga remaja putri tidak malu bertanya kepada orang tuanya. Penelitian yang dilakukan oleh Sooki et al ${ }^{12}$, menyebutkan peran orang tua dalam pendidikan kesehatan termasuk kesehatan reproduksi termasuk dalam kategori baik, karena peran orang tua sebagai pendidik, pengawas, teman dan konselor.

\section{KESIMPULAN}

Kegiatan Generasi Berencana Peduli Organ Reproduksi Perempuan (GenRe POP) dapat menambah pengetahuan remaja tentang pentingnya menjaga kesehatan reproduksi melalui personal menstrual hygiene. Selain itu keterlibatan para ibu dalam meningkatkan personal menstrual hygiene remaja juga menjadi faktor penting mewujudkan generasi remaja yang peduli kesehatan reproduksi. Para ibu dapat berperan sebagai pendidik, pengawas, teman dan konselor bagi remaja dalam meningkatkan personal menstrual hygiene.

\section{UCAPAN TERIMA KASIH}

Terima kasih kami ucapkan kepada pihak STIKes RS Husada yang telah mendukung kegiatan ini dalam hal moril maupun materiil. Tak lupa juga ucapan terima kasih kepada pihak RT.007 RW.10 Kecamatan Sukmajaya Depok yang mendukung kegiatan pengabdian kepada masyarakat ini.

\section{DAFTAR PUSTAKA}

1. BPS. Sensus Penduduk Indonesia Tahun 2020. Jakarta; 2020.

2. Borjigen A, Huang C, Liu M, Lu J, Peng H, Sapkota C, et al. Status and factors of menstrual knowledge, attitudes, behaviors and their correlation with psychological stress in adolescent girls. J Pediatr Adolesc Gynecol [Internet]. 2019;32(6):584-9. Available from: https://pubmed.ncbi.nlm.nih.gov/31445139/

3. Masan L, Frelestanty E. Hubungan Pengetahuan Dengan Sikap Remaja Putri Kelas VII Dalam Menghadapi Menarche. J Kebidanan [Internet]. 2018; Available from https://www.researchgate.net/ publication/334595362_Hubungan_Pengetahuan_Dengan_Sikap_Remaja_Putri_Kelas_VII_Dalam_Men ghadapi_Menarche_Di_SMP_Negeri_02_Sintang_Tahun_2017.

4. Azzahra N, Adiwiryono RM. Faktor-Faktor Yang Berhubungan Dengan Perilaku Personal Hygiene Saat Menstruasi Pada Siswi SMP PGRI Depok II Tengah Jawa Barat Tahun 2020. J Pendidik Kesehat [Internet]. 2020;9 (2) : 211-20. Available from: https://ojs.poltekkes-malang.ac.id/index.php/jpk/ article/view/2030/310

5. Amanda D, Ariyanti F. Perilaku Menstrual Hygiene Remaja: Studi Pada Santriwati Di Pondok Pesantren Modern Kota Depok. J Publ Kesehat Masy Indones [Internet]. 2020;7(2). Available from: https:// ppjp.ulm.ac.id/journal/index.php/JPKMI/article/view/10169/6831

6. Hidayah IY, Hardiani RS, Hakam M. Pengaruh Metode Biblioterapi terhadap Pengetahuan Remajatentang Hygiene Menstruasi di SMP Negeri 2 MayangKabupaten Jember. e-Jurnal Pustaka Kesehat [Internet]. 2016;4(2). Available from: https://jurnal.unej.ac.id/index.php/JPK/article/ view/3206/2551

7. Ningsih WA, Suseno MR, Hamidiyanti BYF. Pengaruh Pendidikan Kesehatan Menggunakan Media Video Dan Alat Peraga Terhadap Pengetahuan Dan Sikap Remaja Putri Tentang Personal Hygiene Pada Masa Menstruasi Dalam Layanan Homecare Di Dusun Kumbung Wilayah Kerja Puskesmas Kuripan Kabupaten Lombok Barat . J Kebidanan [Internet]. 2021;10(2). Available from: https://akbiddharmahusadakediri.e-journal.id/JKDH/index

This is an open-access article under the CC BY 4.0 International License

(c) Idea PengabdianMasyarakat (2022)

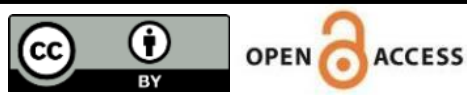


8. Zuhriya C, Armini NKA, Wahyuni ED. Pengaruh Edutainment Ular Tangga Terhadap Perilaku Remaja Tentang Personal Hygiene Menstruasi. J Keperawatan Muhammadiyah. 2018;3(2).

9. Ejike CU, Oluwole AS, Mogaji HO, Adeniran AA, Alabi OM, Ekpo UF. Development and testing of Schisto and Ladders ${ }^{\mathrm{TM}}$, an innovative health educational game for control of schistosomiasis in schoolchildren. BMC Res Notes [Internet]. 2017;10(236). Available from: https://www.ncbi.nlm.nih.gov/pmc/articles/PMC5490240/pdf/13104 2017 Article 2545.pdf

10. itrizah MK, Raksanagara AS, Agoes R. The Effect Of Snakes And Ladders Game To Improve Knowledge And Attitudes Of Elementary School Students To Stop Open Defication In Bandung City. Indones J Public Heal [Internet]. 2020;15(2):173-80. Available from: https://ejournal.unair.ac.id/IJPH/article/view/13283/pdf

11. Kurniawati D, Rohmana DY, Juliningrum PP. Pengaruh Permainan Ular Tangga terhadap Pengetahuan dan Sikap dalam Menghadapi Menarche pada Siswi SDN Pringgowirawan 01 Sumberbaru Kabupaten Jember. 2017.

12. Sooki Z, Shariati M, Chaman R, Khosravi A, Effatpanah M, Keramat A. The Role of Mother in Informing Girls About Puberty: A Meta-Analysis Study. Nurs Midwifery Stud [Internet]. 2016;5(1). Available from: https://www.ncbi.nlm.nih.gov/pmc/articles/PMC4915208/pdf/nms-05-01-30360.pdf 